\title{
Our recommendations for acute management of COVID-19
}

\author{
Francesco Mojoli ${ }^{1,2}$, Silvia Mongodi ${ }^{2,3^{*}}$ (D), Anita Orlando ${ }^{2}$, Eric Arisi ${ }^{2}$, Marco Pozzi $^{2}$, Luca Civardi ${ }^{2}$, Guido Tavazzi ${ }^{1,2}$, \\ Fausto Baldanti ${ }^{1,4}$, Raffaele Bruno ${ }^{1,5}$, Giorgio Antonio lotti ${ }^{1,2}$ and COVID-19 Pavia Crisis Unit
}

Keywords: ARDS, COVID-19, Acute respiratory failure, Lung ultrasound, Novel coronavirus

The 2019 coronavirus disease (COVID-19) epidemic is currently spreading worldwide; in particular, Italy and our region (Lombardy) have been facing the largest European outbreak since February 21st [1]. We here share our practical clinical management suggestions, derived from the direct experience of the first 200 patients with acute respiratory failure, of which 75 were finally admitted to intensive care unit (ICU) to undergo mechanical ventilation:

1. Suggestive clinical picture includes upper airways disease, with cough, fever and flu-like syndrome, evolving to dyspnoea after 2-10 days and presenting with bilateral chest infiltrates. Blood gas analysis initially shows moderate hypoxaemia, metabolic acidosis with/without respiratory compensation, normal lactates and increased anion gap; ketoacids are found in urinary sticks. Blood samples show high C-reactive protein, normal procalcitonin, increased lactate dehydrogenase, creatine phosphokinase, amylases, lipases and hyperglycaemia. A nasal swab for 2019 novel coronavirus is routinely performed in any upper/lower airways disease [2].

2. In suggestive clinical pictures, do not trust negative nasal swab: patients may have negative swabs but positive bronchoalveolar lavage. We suggest isolating suspected patients and using personal

\footnotetext{
* Correspondence: silvia.mongodi@libero.it

${ }^{2}$ Anaesthesia and Intensive Care, San Matteo Hospital, Pavia, Italy

${ }^{3}$ Rianimazione I, Fondazione IRCCS Policlinico S. Matteo, DEA piano -1, Viale Golgi 19, 27100 Pavia, Italy

Full list of author information is available at the end of the article
}

protective equipment as if positive; eventually, repeat the nasal swab and perform a bronchoalveolar lavage if possible. Rule out other potential aetiologies of acute respiratory failure with microbiological sampling, urinary antigens for Streptococcus pneumoniae and Legionella pneumoniae, serologies for atypical bacterial pneumonia and search of other respiratory viruses $[3,4]$.

3. Increase the number of ICU beds and prepare the wards to provide non-invasive ventilation: once the epidemic starts, patients requiring respiratory support increase exponentially. Organize a shared dataset of patients with non-invasive ventilation in the wards [5] and a daily round by an intensivist, to early identify the failing patients.

4. Set up specific therapy early in all positive/ suspected patients: we systematically introduce hydroxychloroquine $200 \mathrm{mg}$ tid and azithromycin $500 \mathrm{mg}$ per day; prophylaxis is started with trimethoprim/sulphamethoxazole 2 vials/day if lymphopaenia, which is frequent. Discuss the potential interest of remdesivir $100 \mathrm{mg} /$ day with infectious disease consultant. Consider introducing empiric antibiotic therapy, to be stopped in case of negative microbiological samples and negative procalcitonin [4].

5. Correct metabolic acidosis and hyperglycaemia early to decrease respiratory load with insulin infusion (target glycaemia $<150 \mathrm{mg} / \mathrm{dL}$ ); if negative base excess persists at blood gas 
analysis, consider sodium bicarbonate infusion (starting dose $20 \mathrm{mEq} / \mathrm{h}$ ).

6. Most of the patients respond to positive endexpiratory pressure: prefer helmet to mask for a continuous positive airway pressure trial to set moderate-high positive end-expiratory pressure ( $>8 \mathrm{cmH}_{2} \mathrm{O}$ ), improve patient's tolerance to prolong non-invasive support and prevent droplets' spread [4]. For this same purpose, add a highefficiency particulate air filter before the positive end-expiratory pressure valve or, better, connect the valve to wall gas aspiration [6-8].

7. Perform early intubation if poor response to continuous positive airway pressure in terms of oxygenation: do not trust patients' relatively good respiratory mechanics and feeling of improved dyspnoea, since these patients may have relatively normal lung compliance and the only clinical sign of fatigue may be high respiratory rate. Connect ventilator expiratory valve to wall gas aspiration to limit droplets' spread.

8. Once intubated, perform a closed system bronchoalveolar lavage to confirm diagnosis: minimize the use of fiberbronchoscopes to limit airways' opening; we connect a bronchoalveolar lavage test tube to the closed aspiration system-mandatory in these patients-for deep bronchial sampling. Thereafter, repeat the sampling every 7 days for viral charge assessment and bacterial over-infection detection [4].

9. After intubation, evaluate basic lung mechanics: it usually shows a respiratory system compliance of $0.5-1 \mathrm{ml} / \mathrm{cmH}_{2} \mathrm{O}$ per kilogramme of predicted body weight with high recruitability at pressure-volume curve and normal resistances. These patients usually show good response to high positive end-expiratory pressure levels; calibrated oesophageal pressure may help its setting [9]. Consider neuromuscular blocking agents if deep sedation does not control the patient's trigger and ventilation is not protective; perform daily a trial of neuromuscular blocking agents stop.

10. Prefer lung ultrasound to other imaging techniques: it is accurate in interstitial diseases and may show pathological signs before chest X-ray. A basic assessment helps deciding the ventilatory strategy: if diffuse loss of aeration, keep high positive endexpiratory pressure levels; if posterior consolidations, consider pronation. Lung ultrasound may also help in limiting traditional imaging, avoiding patients' transportation to radiology department. It also allows a daily monitoring of clinical evolution, response to treatment and possible complications (pneumothorax, over-infections) [10-12].
11. Avoid positive fluid balance: perform fluid challenges and stop fluid resuscitation if no haemodynamic response; use vasoactive drugs instead to optimize tissue perfusion [4]. We accept moderate elevation of creatinine without urinary output impairment to improve the lung status.

12. Fever is a frequent issue, reaching values as high as $40^{\circ} \mathrm{C}$; we decided to treat it only if $>39^{\circ} \mathrm{C}$, if oxygenation is acceptable. Spontaneous defervescence can be the first sign of clinical improvement.

13. As soon as possible according to gas exchanges $\left(\mathrm{PaO}_{2} / \mathrm{FiO}_{2}>150\right.$ with $\left.\mathrm{FiO} 2<50 \%\right)$ and lung ultrasound score $(\leq 12)$, start assisted ventilation with a sigh while maintaining moderate to high positive end-expiratory pressure to prevent derecruitment. Regularly check patient's respiratory drive (P0.1), tidal volume and plateau pressure to keep ventilation safe. Dexmedetomidine may help in the weaning phase.

14. In patients having received prolonged sedation, we frequently observed prolonged awakening with altered respiratory drive and difficult patientventilator interaction; if no prompt awakening is observed, perform early tracheostomy to accelerate the weaning and discharge from ICU. The number of patients requiring intensive care rapidly increases; therefore, rapid discharge is mandatory.

15. Hyperinflammatory status increases the risk of thrombosis and pulmonary embolism; check for thrombotic complications systematically, mainly in correspondence of central lines [13, 14].

16. Communication with families is difficult since patients' relatives are frequently in quarantine and access to the hospital is limited; moreover, while wearing personal protective equipment, physicians' possibility to answer to relatives' phone call is limited. Consider identifying each day one person in charge of phone calls to daily update relatives on clinical conditions [15].

We hope sharing our experience while facing the Italian outbreak of 2019 novel coronavirus may help other Units eventually facing the same threat in the future.

Abbreviations

SARS-CoV-2: Severe acute respiratory syndrome coronavirus 2; ICU: Intensive care unit

\section{Acknowledgements}

We thank all the healthcare professionals involved in the management of such epidemics, in particular nurses and physicians of Intensive Care Unit at S. Matteo Hospital. 


\section{Authors' contributions}

All the authors actively contributed to the conception, redaction and final revision before submission of the manuscript. The authors read and approved the final manuscript.

\section{Funding}

None

\section{Availability of data and materials}

Not applicable

\section{Ethics approval and consent to participate}

Not applicable

\section{Consent for publication}

Not applicable

\section{Competing interests}

FM received fees for lectures from GE Healthcare, Hamilton Medical, SEDA $\mathrm{SpA}$, outside the present work. SM received fees for lectures from GE Healthcare, outside the present work. AO received fees for the manuscript preparation from Hamilton Medical, outside the present work. MP received fees for lectures from Hamilton Medical, outside the present work. LC received fees for lectures by GE Healthcare, outside the present work. GT received fees for lectures by GE Healthcare, outside the present work. GAl received fees for lectures by Hamilton Medical, Eurosets, Getinge, Intersurgical SpA and Burke\&Burke, outside the present work. A research agreement is active between University of Pavia and Hamilton Medical, outside the present work.

\section{Author details}

'Department of Clinical-Surgical, Diagnostic and Paediatric Sciences, Unit of Anaesthesia and Intensive Care, University of Pavia, Pavia, Italy. ${ }^{2}$ Anaesthesia and Intensive Care, San Matteo Hospital, Pavia, Italy. ${ }^{3}$ Rianimazione I, Fondazione IRCCS Policlinico S. Matteo, DEA piano -1, Viale Golgi 19, 27100 Pavia, Italy. ${ }^{4}$ Molecular Virology Unit, Microbiology and Virology Department, San Matteo Hospital, Pavia, Italy. Infectious Diseases, San Matteo Hospital, Pavia, Italy.

Received: 27 March 2020 Accepted: 27 April 2020

Published online: 08 May 2020

\section{References}

1. Grasselli G, Pesenti A, Cecconi M. Critical care utilization for the COVID-19 outbreak in Lombardy, Italy: early experience and forecast during an emergency response. JAMA. 2020. https://doi.org/10.1001/jama.2020.4031 [Epub ahead of print].

2. Wu Z, McGoogan JM. Characteristics of and important lessons from the coronavirus disease 2019 (COVID-19) outbreak in China: summary of a report of 72314 cases from the Chinese Center for Disease Control and Prevention. JAMA. 2020. https://doi.org/10.1001/jama.2020.2648 [Epub ahead of print].

3. Bouadma L, Lescure FX, Lucet JC, Yazdanpanah Y, Timsit JF. Severe SARSCoV-2 infections: practical considerations and management strategy for intensivists. Intensive Care Med. 2020. https://doi.org/10.1007/s00134-02005967-x [Epub ahead of print].

4. Alhazzani W, Hylander Møller M, Arabi YM, et al. Surviving sepsis campaign guidelines on the management of critically ill adults with coronavirus disease 2019 (COVID-19). Intensive Care Med. 2020; [Un-edited accepted Proof - https://www.esicm.org/wp-content/uploads/2020/03/SSC-COVID19GUIDELINES.pdf]

5. Asperges E, Novati S, Muzzi A, et al. Rapid response to COVID-19 outbreak in Northern Italy: how to convert a classic infectious disease ward into a COVID-19 response centre. J Hosp Infect. 2020. https://doi.org/10.1016/j.jhin. 2020.03.020 [Epub ahead of print].

6. Patel BK, Wolfe KS, Pohlman AS, Hall JB, Kress JP. Effect of noninvasive ventilation delivered by helmet vs face mask on the rate of endotracheal intubation in patients with acute respiratory distress syndrome: a randomized clinical trial. JAMA. 2016;315(22):2435-41.
7. Arabi YM, Fowler R, Hayden FG. Critical care management of adults with community-acquired severe respiratory viral infection. Intensive Care Med. 2020;46(2):315-28. https://doi.org/10.1007/s00134-020-05943-5.

8. Clinical management of severe acute respiratory infection when Novel coronavirus (2019-nCoV) infection is suspected: Interim Guidance 28 January 2020. World Health Organisation https://apps.who.int/iris/ handle/10665/330893.

9. Mauri T, Yoshida T, Bellani G, et al. Esophageal and transpulmonary pressure in the clinical setting: meaning, usefulness and perspectives. Intensive Care Med. 2016;42(9):1360-73 Intensive Care Med 2016;42(9):1360-73.

10. Mojoli F, Bouhemad B, Mongodi S, Lichtenstein D. Lung ultrasound for critically ill patients. Am J Respir Crit Care Med. 2019;199(6):701-14.

11. Chiumello D, Mongodi S, Algieri I, et al. Assessment of lung aeration and recruitment by $C T$ scan and ultrasound in acute respiratory distress syndrome patients. Critical Care Med. 2018:46(11):1761-8.

12. Mongodi S, Via G, Girard M, et al. Lung ultrasound for early diagnosis of ventilator-associated pneumonia. Chest. 2016;149(4):969-80.

13. Wu C, Chen X, Cai Y, et al. Risk factors associated with acute respiratory distress syndrome and death in patients with coronavirus disease 2019 pneumonia in Wuhan, China. JAMA Intern Med. 2020. https://doi.org/10. 1001/jamainternmed.2020.0994 [Epub ahead of print].

14. Tavazzi G, Civardi L, Caneva L, Mongodi S, Mojoli F. Thrombotic events in SARS-Cov 2 patients: an urgent call for ultrasound screening. Intensive Care Med. 2020. https://doi.org/10.1007/s00134-020-06040-3 [Epub ahead of print].

15. Mojoli F, Mongodi S, Grugnetti G, et al. Setup of a dedicated coronavirus intensive care unit: logistical aspects. Anesthesiology. 2020. https://doi.org/ 10.1097/ALN.0000000000003325 [Epub ahead of print].

\section{Publisher's Note}

Springer Nature remains neutral with regard to jurisdictional claims in published maps and institutional affiliations. 